\title{
Simulating 3-D radiative transfer effects over the Sierra Nevada Mountains using WRF
}

\author{
Y. Gu ${ }^{1}$, K. N. Liou ${ }^{1}$, W.-L. Lee ${ }^{2}$, and L. R. Leung ${ }^{3}$ \\ ${ }^{1}$ Joint Institute for Regional Earth System Science and Engineering, Department of Atmospheric and Oceanic Sciences, \\ University of California, Los Angeles, CA 90095, USA \\ ${ }^{2}$ Research Center for Environmental Changes, Academia Sinica, Taipei, Taiwan \\ ${ }^{3}$ Pacific Northwest National Laboratory, Richland, WA, USA
}

Correspondence to: Y. Gu (gu@atmos.ucla.edu)

Received: 17 July 2012 - Published in Atmos. Chem. Phys. Discuss.: 9 August 2012

Revised: 12 October 2012 - Accepted: 17 October 2012 - Published: 30 October 2012

\begin{abstract}
A surface solar radiation parameterization based on deviations between 3-D and conventional plane-parallel radiative transfer models has been incorporated into the Weather Research and Forecasting (WRF) model to understand the solar insolation over mountain/snow areas and to investigate the impact of the spatial and temporal distribution and variation of surface solar fluxes on land-surface processes. Using the Sierra-Nevada in the western United States as a testbed, we show that mountain effect could produce up to -50 to $+50 \mathrm{~W} \mathrm{~m}^{-2}$ deviations in the surface solar fluxes over the mountain areas, resulting in a temperature increase of up to $1{ }^{\circ} \mathrm{C}$ on the sunny side. Upward surface sensible and latent heat fluxes are modulated accordingly to compensate for the change in surface solar fluxes. Snow water equivalent and surface albedo both show decreases on the sunny side of the mountains, indicating more snowmelt and hence reduced snow albedo associated with more solar insolation due to mountain effect. Soil moisture increases on the sunny side of the mountains due to enhanced snowmelt, while decreases on the shaded side. Substantial differences are found in the morning hours from 8-10 a.m. and in the afternoon around $3-5$ p.m., while differences around noon and in the early morning and late afternoon are comparatively smaller. Variation in the surface energy balance can also affect atmospheric processes, such as cloud fields, through the modulation of vertical thermal structure. Negative changes of up to $-40 \mathrm{~g} \mathrm{~m}^{-2}$ are found in the cloud water path, associated with reductions in the surface insolation over the cloud region. The day-averaged deviations in the surface solar flux are positive over the mountain areas and negative in the valleys, with
\end{abstract}

a range between $-12 \sim 12 \mathrm{~W} \mathrm{~m}^{-2}$. Changes in sensible and latent heat fluxes and surface skin temperature follow the solar insolation pattern. Differences in the domain-averaged diurnal variation over the Sierras show that the mountain area receives more solar insolation during early morning and late afternoon, resulting in enhanced upward sensible heat and latent heat fluxes from the surface and a corresponding increase in surface skin temperature. During the middle of the day, however, the surface insolation and heat fluxes show negative changes, indicating a cooling effect. Hence overall, the diurnal variations of surface temperature and surface fluxes in the Sierra-Nevada are reduced through the interactions of radiative transfer and mountains. The hourly differences of the surface solar insolation in higher elevated regions, however, show smaller magnitude in negative changes during the middle of the day and possibly more solar fluxes received during the whole day.

\section{Introduction}

The energy emitted by the sun and received by the Earth's surface is determined by three sets of factors. The first includes latitude, solar hour angle, and the Earth's position relative to the sun, which determines the incoming solar radiation at the top of the atmosphere and can be precisely calculated (Liou, 2002). The second involves the attenuation of a solar beam by scattering and absorption caused by atmospheric gases, aerosols, and cloud particles. The last is comprised of terrain characteristics, including elevation, 
slope, orientation, and surface albedo. On a sloping surface in mountainous terrain, the total solar radiation can be separated into a number of components according to the sunto-surface path: direct and diffuse, their reflections from the mountain surface, and multiple reflections between mountains. The spatial and temporal distributions of surface solar radiation are the primary driving forces behind many climatic processes, including snowmelt, soil moistening, photosynthesis, vegetation, and evapotranspiration (Geiger, 1965; Bonan, 2002; Gu et al., 2002; Müller and Scherer, 2005). Owing to the intricacy of spatial orientation and inhomogeneous features of mountain topography and the complexity of interactions of direct and diffuse solar beams with mountain surfaces, quantifying these interactions and reliably determining total surface solar fluxes for incorporation in a land-surface energy balance model has been a challenging task yet to be accomplished in regional and global climate modeling.

In our previous studies, we have developed a Monte Carlo photon tracing program for 3-D radiative transfer for application to mountains/snow and ocean surfaces (Chen et al., 2006; Lee and Liou, 2007; Liou et al., 2008). We demonstrated that the effect of mountains on surface radiative balance is substantial in terms of subgrid variability as well as domain average conditions. In particular, we showed pertinent results for solar and IR radiative transfer for a $200 \times 200 \mathrm{~km}^{2}$ region centered at Lhasa over the Tibetan Plateau, employing $1 \times 1 \mathrm{~km}^{2}$ elevation data and $5 \times 5 \mathrm{~km}^{2}$ MODIS albedo data as boundary conditions in broadband flux calculations. A significant solar flux deviation of about $10-35 \mathrm{~W} \mathrm{~m}^{-2}$ from the flat surface of conventional GCMs and regional climate models would occur if realistic mountain features were not accounted for in surface energy balance modeling (Liou et al., 2007; Lee et al., 2011, 2012). An error of such magnitude would have a substantial effect on the surface energy budgets over snow-covered mountains due to snow-albedo feedback, with significant ramifications for the seasonal variations of snowpack, runoff, and soil moisture, as well as the diabatic heating that drives regional and large-scale circulations.

In Lee et al. (2011), a parameterization for the five components of surface solar fluxes was developed on the basis of differences between 3-D and plane-parallel radiative transfer results simulated from a Monte Carlo photon tracing program for clear sky. The resulting differences for the five flux components were shown to be linear functions of a combination of several key variables defining the terrain configuration with respect to the sun's position with high correlation. We have incorporated this parameterization into the Weather Research and Forecasting (WRF) model (Skamarock et al., 2005) to investigate the impact of 3-D mountains over the Sierra-Nevada areas on the simulated surface solar insolation patterns and associated sensible and latent heat fluxes, as well as the surface skin temperature. In Sect. 2 we present a brief discussion on the 3-D parameterization for surface solar radiation over mountain surfaces. Section 3 describes the WRF experiment design, real case simulations, and comparison of the results from different experiments, including a discussion on the potential impact of 3-D parameterization of surface solar radiation on climate simulations. Conclusions are given in Sect. 4.

\section{3-D radiative transfer in mountains/snow}

We have selected a rugged area of the Sierra-Nevada Mountains in the Western United States (Fig. 1a), which is comprised of a variety of elevations and slopes, as an experimental testbed. The surface topography with a $1 \mathrm{~km}$ resolution was taken from the HYDRO1k geographic database available from the USGS National Center for Earth Resources Observation and Science data center. This area is divided into eighty $20 \times 20 \mathrm{~km}^{2}$ domains to represent the general terrain characteristics and topographical variations (Fig. 1b). In order to reduce the edge effect caused by the cyclic boundary condition used in the Monte Carlo photon tracing model, only the topographic information and surface radiative fluxes in the central $10 \times 10 \mathrm{~km}^{2}$ areas were used to develop the regression parameterization. We have largely employed a uniform surface albedo value in the Monte Carlo simulations; however, high-resolution albedo values were included in parameterization analysis when appropriate.

Solar radiative fluxes can be categorized into five components according to photon path: $(1)$ direct flux $\left(F_{\text {dir }}\right)$ is composed of photons hitting the ground directly from the sun without encountering scattering or reflection; (2) diffuse flux $\left(F_{\text {dif }}\right)$ contains photons experiencing single or multiple scattering by air molecules, but does not encounter surface reflection; (3) direct-reflected flux $\left(F_{\text {rdir }}\right)$ is comprised of unscattered photons reflected by nearby terrain; (4) diffusereflected flux $\left(F_{\text {rdif }}\right)$ is similar to direct-reflected flux, except that the photon is first scattered by air molecules and then being reflected by nearby terrain; and (5) coupled flux $\left(F_{\text {coup }}\right)$ represents photons that after being reflected by the surface, encounter scattering and/or one or more additional surface reflections. Direct and diffuse fluxes are independent of surface albedo, whereas $F_{\text {rdir }}$ and $F_{\text {rdif }}$ contain photons that have been reflected once and are linearly proportional to surface albedo. Only coupled flux has nonlinear relationship with surface albedo.

In current climate models, conventional plane-parallel radiative transfer schemes have already been developed to calculate solar fluxes on a flat surface with a known elevation. Thus, the purpose of the present parameterization effort is to produce relative deviations of the fluxes from those of a flat surface with the same elevation, given subgrid scale topographic information, which includes the mean values for the sky view factor, the terrain configuration factor, and the cosine of the solar zenith angle, and conventional topographic parameters for each $10 \times 10 \mathrm{~km}^{2}$ domain involving mean elevation and slope in multiple linear regression analysis, along 


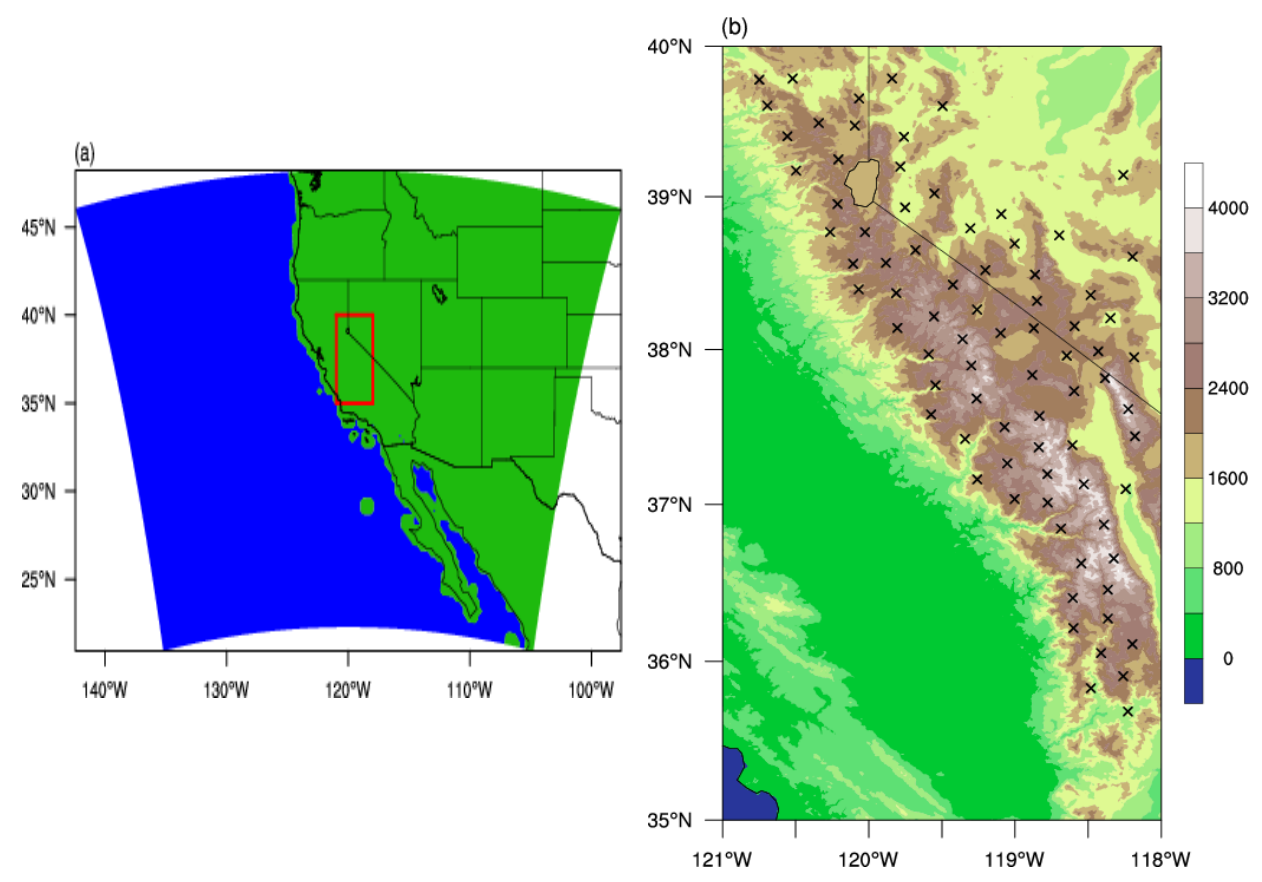

Fig. 1. (a) The domain of the western United States, where the red box denotes the study region over the Sierras. (b) The topography for the study region using the digital elevation model (DEM) at a resolution of $1 \mathrm{~km}$. The scale on the right is in units of meter. The x's represent 80 sub-regions with a resolution of $20 \mathrm{~km}$ from which the parameterization data involving 3-D radiative transfer was derived (Lee et al. 2011).

with their standard deviation and skewness. Following Lee et al. (2011), five sets of the regression equations for flux deviations have been developed, which have the following general matrix form:

$$
\left(\begin{array}{l}
F_{1}^{*} \\
F_{2}^{*} \\
F_{3}^{*} \\
F_{4}^{*} \\
F_{5}^{*}
\end{array}\right)=\left(\begin{array}{l}
a_{1} \\
a_{2} \\
a_{3} \\
a_{4} \\
a_{5}
\end{array}\right)+\left(\begin{array}{ccccc}
b_{11} & b_{12} & 0 & 0 & 0 \\
b_{21} & b_{22} & 0 & b_{24} & b_{25} \\
0 & 0 & b_{33} & b_{34} & b_{35} \\
0 & 0 & b_{43} & b_{44} & b_{45} \\
b_{51} & 0 & b_{53} & b_{54} & 0
\end{array}\right)\left(\begin{array}{l}
y_{1} \\
y_{2} \\
y_{3} \\
y_{4} \\
y_{5}
\end{array}\right)
$$

where $a_{i}(i=1-5)$ is the intercept, $b_{i j}(i, j=1-5)$ are regression coefficients, and $y_{j}(j=1-5)$ is a specific variable. For the index $i, 1=\operatorname{dir}, 2=\operatorname{dif}, 3=\operatorname{rdir}, 4=\operatorname{rdif}$, and $5=$ coup. The parameters for multiple regression analysis are: $y_{1}=\left\langle\mu_{i}\right\rangle$, $y_{2}=\left\langle V_{\mathrm{d}}\right\rangle, y_{3}=\left\langle C_{\mathrm{t}}\right\rangle, y_{4}=\langle h\rangle, y_{5}=\gamma(h)$, where \langle\rangle denotes domain average, and $\gamma(\mathrm{l})$ is the skewness of terrain elevation (or height) $h$ for a target point. The cosine of the solar incident angle $\mu_{i}=\cos \left(\theta_{i}\right)$, where $\theta_{i}$ is defined as the angle between the direction of the incident solar beam and the slope's normal vector of a target point and is a function of solar zenith and azimuthal angles, mountain slope, and slope orientation. An unobstructed horizontal surface (or simply a flat surface) will intercept radiation emitted from the sun in all directions. Over mountainous areas, however, the solar fluxes intercepted at a target point are subject to the blocking of surrounding mountains. Consequently, only a portion of the sky dome can be visible at the target point, which is defined by the term referred to as the sky view factor $V_{\mathrm{d}}$.This parameter represents the shadow effect of the mountains on the direct and diffuse solar fluxes reaching the target point. The term $C_{\mathrm{t}}$ is referred to as the terrain configuration factor, defined as the area of surrounding mountains visible to the target point which determines the solar fluxes reflected to the target point from the surrounding mountains. The parameter $C_{\mathrm{t}}$ will affect the direct- and diffuse-reflected fluxes as well as the coupled flux induced by mountain topography.

The relative deviations of the five components of solar fluxes at the mountain surface are defined by

$F_{i}^{*}=\left(F_{i}-\bar{F}_{i}\right) / \bar{F}_{i}, i=$ dir, dif, coup,

$F_{\text {rdir }}^{*}=F_{\text {rdir }} / \bar{F}_{\text {dir }}$,

$F_{\text {rdif }}^{*}=F_{\text {rdif }} / \bar{F}_{\text {dif }}$,

where $F_{i}$ are the surface solar fluxes over mountain calculated by the 3-D Monte Carlo model (taken as real values), and $\bar{F}_{i}$ are the fluxes calculated with reference to the flat surface. Lee et al. (2011) illustrated that the most significant term is the direct flux, which has high correlations generally larger than 0.9 with root mean square errors less than $3 \mathrm{~W} \mathrm{~m}^{-2}$ (out of $700 \mathrm{~W} \mathrm{~m}^{-2}$ ). Deviations from plane-parallel results are on the order of $100 \mathrm{~W} \mathrm{~m}^{-2}$. The most significant factor determining this flux is the mean solar zenith angle, but the mean sky view factor also has a strong impact because it is an indicator of the shading effect. Deviation of the 3-D diffuse flux from plane-parallel results is only about $3 \mathrm{~W} \mathrm{~m}^{-2}$ 
with elevation, the most significant determining variable. For direct-reflected fluxes, deviation is generally on the order of $3-6 \mathrm{~W} \mathrm{~m}^{-2}$. For diffuse-reflected and coupled fluxes, deviations are about 0.3 and $0.5 \mathrm{~W} \mathrm{~m}^{-2}$, respectively. The dominant factor for these reflected-related fluxes is the terrain configuration factor, followed by the skewness of elevation. The accuracy of the regression model has been carefully analyzed in which the coefficient of multiple regression $R^{2}$ between the results from parameterization and the Monte Carlo calculation (true values) is larger than 0.98 for direct flux component, except for the extreme cases of $\mu_{0}=0.1$ and 1 . This reveals that the regression equation can accurately predict the direct flux, which has variation in its deviation as large as $100 \mathrm{~W} \mathrm{~m}^{-2}$. For other flux components, $R^{2}$ ranges between 0.6-0.9. To examine the compatibility of the parameterization at different horizontal resolutions, surface fluxes over larger domains (up to $50 \times 50 \mathrm{~km}^{2}$ ) using the parameterization have been computed and compared with the "exact" Monte Carlo approach. The resulting coefficient of multiple regression $R^{2}$ between the results determined from the parameterization and the Monte Carlo calculation (true values) is generally larger than 0.95 for all flux components. For this reason, it is concluded that the present parameterization can be directly applied to horizontal resolutions up to $50 \mathrm{~km}$ without additional averaging requirements (Lee et al., 2011).

The present parameterization can be applied to different atmospheric compositions in view of the fact that variation in the trace gas concentrations (such as water vapor) only alters the absorption coefficient associated with the number of absorbed photons, while the number and direction of the scattered photons remain unchanged in Rayleigh atmospheres. Because the effect due to change in the atmospheric absorption coefficient has already been accounted for in conventional radiative transfer schemes, the present parameterization, which is in reference to deviations from plane-parallel radiative transfer results, can be directly applied to different atmospheric conditions. When clouds are present, equations for $F_{\text {dir }}^{*}$ and $F_{\text {rdir }}^{*}$ will remain unchanged since these terms involve direct attenuation only. The current regression equations developed for $F_{\text {dif }}^{*}, F_{\text {rdif }}^{*}$, and $F_{\text {coup }}^{*}$, which are small values as compared to $F_{\text {dir }}^{*}$ and $F_{\text {rdir }}^{*}$, could serve as the first-order approximation for corrections to surface solar fluxes determined from plane-parallel radiative transfer models over mountains covered by clouds. Additionally, in the investigation of the dependence of horizontal resolution, it was found that the basic parameterization data derived for domains at $10 \mathrm{~km}$ resolution can be directly applied to horizontal resolutions up to $50 \mathrm{~km}$ without additional averaging requirements.

\section{Incorporation of 3-D radiative transfer parameterization into WRF and model simulations}

The WRF model (Skamarock et al., 2005) is fully compressible and nonhydrostatic, which is suitable for a broad spectrum of applications across scales ranging from a few meters to thousands of kilometers. Several physics components have been included in WRF, including cloud microphysics, cumulus parameterization, planetary boundary layer, surface layer, land-surface parameterization, and longwave and shortwave radiation. In this study, we have employed Lin scheme (Lin et al., 1983; Rutledge and Hobbs, 1984) for microphysics, Kain-Fritsch cumulus scheme (Kain and Fritsch, 1990, 1993), MRF scheme for planetary boundary layer (Hong and Pan, 1996), MM5 surface layer scheme (Paulson, 1970; Dyer and Hicks, 1970; Webb, 1970; Beljaars, 1994; Zhang and Anthes, 1982), and Noah land-surface model (LSM) which is a 4-layer soil temperature and moisture model with canopy moisture and snow cover prediction (Chen and Dudhia, 2001).

We have recently implemented a more physically-based, consistent and efficient spectral radiation scheme that can effectively resolve the spectral bands, determine the cloud optical properties, and provide more reliable and accurate radiative heating fields in WRF (Gu et al., 2010, 2011). The new radiation module, the Fu-Liou-Gu parameterization, is a modified and improved version based on the Fu-Liou radiative transfer parameterization (Fu and Liou, 1992, 1993). To test the compatibility of the newly developed radiative transfer and cloud microphysics module in WRF, a number of WRF simulations have been carried out for cirrus cases that were observed in the coastal and western United States on 29-30 March 2007, and compared with available observations from MODIS and GOES-IR images over the same areas. The newly implemented Fu-Liou-Gu radiation module has been demonstrated to work well in WRF and can be effectively used for spectral radiative flux calculations over a flat surface in association with a land surface energy balance model (Gu et al., 2011).

The solar flux at the top of the atmosphere is governed by the cosine of the solar zenith angle, $\mu_{0}$, which is defined by the latitude, time of year, and the solar declination angle and is therefore seasonally dependent. The seasonal variation in the sun's position is defined by the values of $\mu_{0}$. When time of year is given, $\mu_{0}$ can then be computed from known mathematical expressions. In reference to the discussion in Sect. 2, values of the regression coefficients for seven different solar zenith angles (SZA) have been determined, including $\mu_{0}=0.1,0.25,0.4,0.55,0.7,0.85$, and 1 for the direct and diffuse components, direct- and diffuse-reflected components, and coupled flux. For SZA between the seven set values, the relative deviations can be obtained by linear interpolation. Note that the current regression coefficients are derived based on Monte Carlo simulations with a surface albedo of $0.1 . F_{\text {rdir }}^{*}$ and $F_{\text {rdif }}^{*}$ are proportional to surface 
(a)

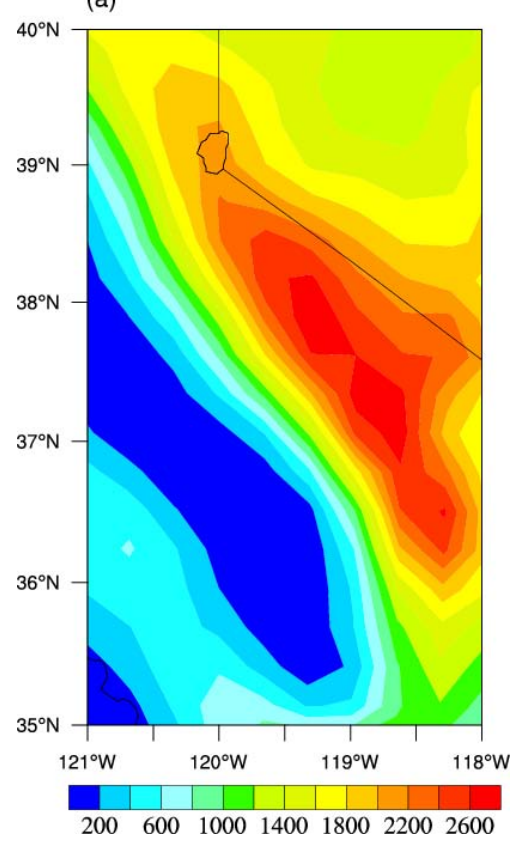

(b)

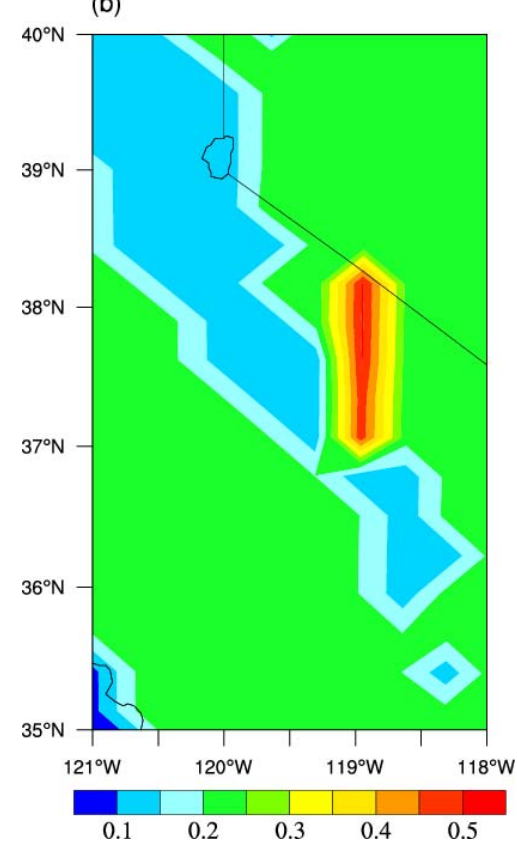

(c)

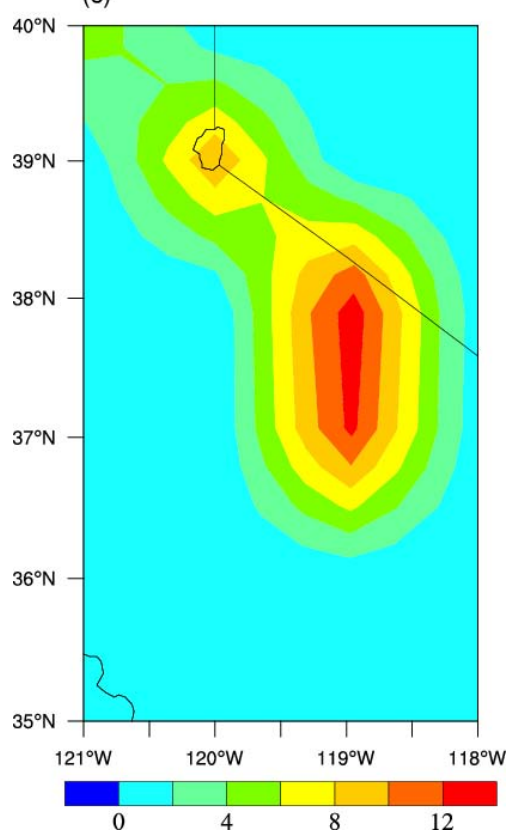

Fig. 2. Maps of the (a) elevation, (b) surface albedo, and (b) snow water equivalent $\left(\mathrm{kg} \mathrm{m}^{-2}\right)$ used in WRF simulations $\left(30 \times 30 \mathrm{~km}^{2}\right.$ resolution) in the Sierra-Nevada area.

albedo and have been linearly scaled with respect to surface albedo after linear interpolation with respect to SZA. Since the value $F_{\text {coup }}^{*}$ is not a linear function with respect to surface albedo, 4 sets of coefficients that cover a range of albedo are employed in determining the regression coefficients.

\subsection{Experiment design}

A domain covering the Sierra-Nevada Mountains in the Western United States, which is comprised of a variety of elevations and slopes, has been selected as an experimental testbed. The model domain has been selected to center at $35^{\circ} \mathrm{N}-120^{\circ} \mathrm{W}$ and cover the area from $135-105^{\circ} \mathrm{W}$ and $20-45^{\circ} \mathrm{N}$, as shown in Fig. 1a where the red box denotes the study region over the Sierras. The horizontal resolution is $30 \times 30 \mathrm{~km}$ together with a vertical resolution of 28 model levels. Data provided by the National Centers for Environmental Prediction (NCEP) Final (FNL) Operational Global Analysis available from the Global Forecast System (GFS) every $6 \mathrm{~h}$ on $1.0 \times 1.0$ degree grids were used as initial and boundary condition. Model integrations have been performed starting on 29 March 2007, at 00:00 UTC for 48 hours. This case is selected because (1) this real-time simulation for this case using WRF with newly incorporated FuLiou-Gu scheme has been examined and validated (Gu et al. 2011) and (2) the Sierra-Nevada area was rather clear during this time period and would be ideal to illustrate the largest possible impact of the 3-D mountains. Additional simulations using different initial conditions for this time period have also been performed, but we found insignificant dif- ferences between model results from different initializations. Note that the focus of this study is to incorporate a 3-D radiative transfer parameterization in WRF to investigate the impact of 3-D mountains on the simulated surface fluxes and surface skin temperature for a short time period. A long-term climate simulations will be needed in order to investigate the associated snow cover change and snow albedo feed back.

To investigate the impact of 3-D parameterization of surface solar radiation on land-surface processes, we have designed the following two experiments:

(1) The CTRL experiment is the control run in which the Fu-Liou-Gu radiation scheme is used over flat surfaces.

(2) The RAD_3-D experiment is identical to CTRL, except that the parameterization for 3-D solar flux deviations over the Sierra-Nevada mountain areas has been implemented in the Fu-Liou-Gu radiation scheme.

\subsection{Simulation results}

Surface elevation for the Sierra-Nevada area used in the WRF simulations is displayed in Fig. 2a. Radiation transfer calculations for both experiments are computed down to the surfaces as determined by the elevation. Surface albedo and snow water equivalent at the beginning of the two-day simulations are displayed in Fig. $2 b$ and c. Snow water is mostly located along the mountain ridges and on the north side of the mountains. Larger surface albedo (up to $\sim 0.5$ ) resides at the center of snow water contour. 
(a)

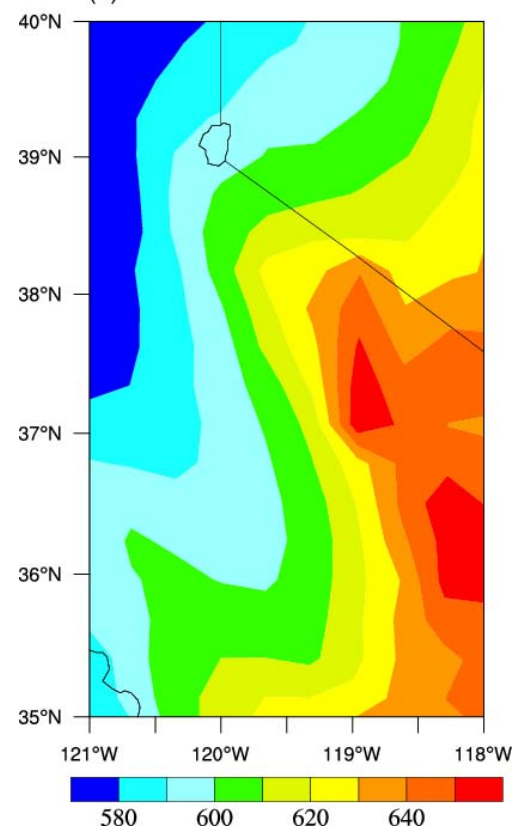

(b)

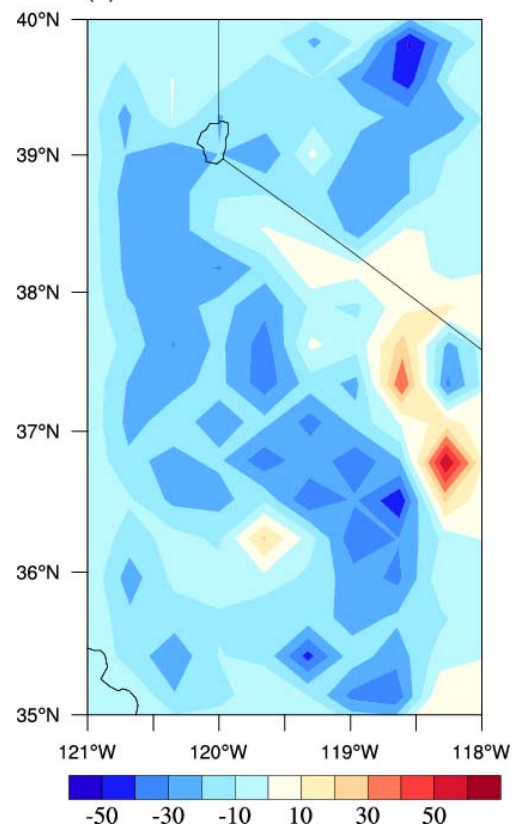

(c)

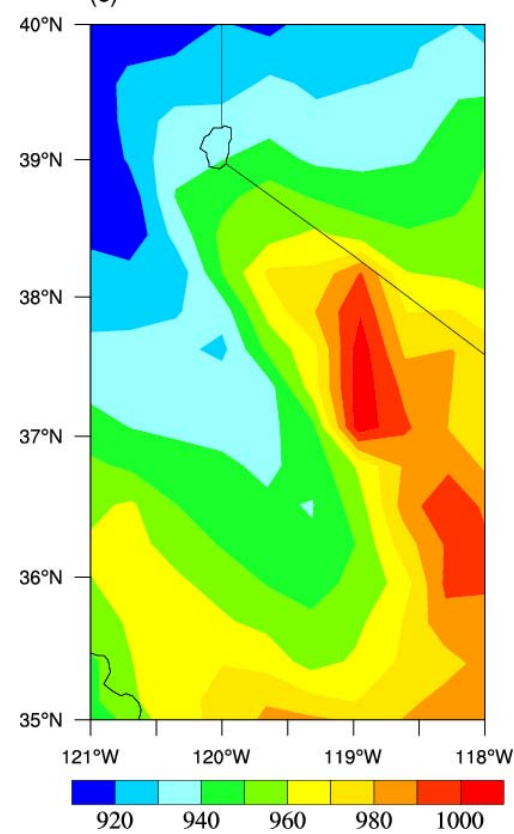

(d)

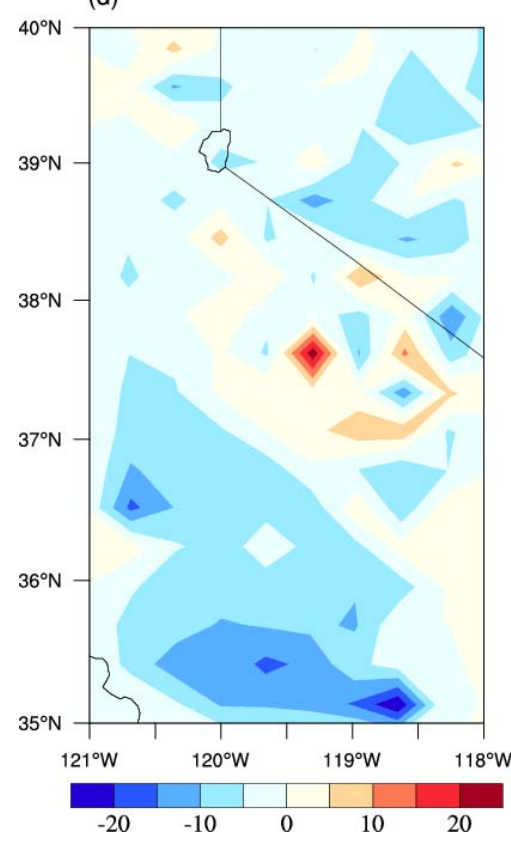

(e)
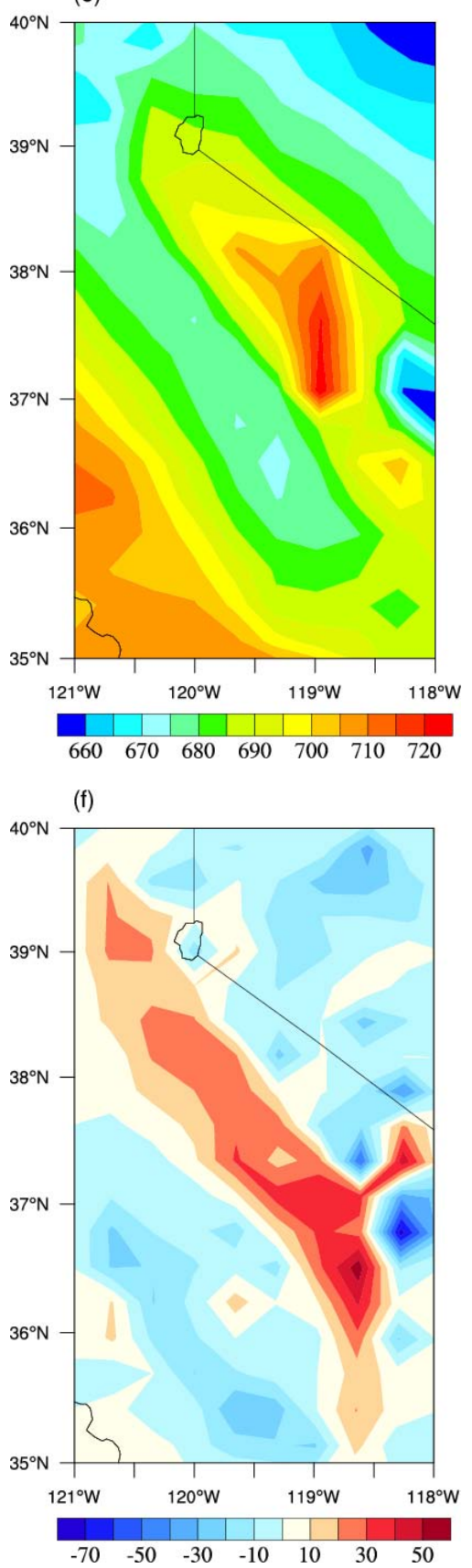

Fig. 3. Downward surface solar fluxes $\left(\mathrm{W} \mathrm{m}^{-2}\right.$ ) over the Sierra-Nevada Mountain for a flat surface (top panel) and their deviations (bottom panel) for 9 a.m. (left panel), 12 p.m. (middle panel), and 3 p.m. (right panel) of local time on 29 March 2007.

Figure 3 displays the downward surface solar fluxes over the Sierras for a flat surface (top panel) and their deviations (bottom panel) for 9 a.m. (left panel), 12 p.m. (middle panel), and 3 p.m. (right panel) of local time on 29 March 2007. The results for March 30, 2007 have similar patterns and are not shown. The maximum downward solar fluxes in the CTRL experiment are normally located at the highest elevation due to less attenuation of the solar fluxes in the at- mosphere (Fig. 3a, c, and e). In the morning, strong positive anomalies on the order of $50 \mathrm{~W} \mathrm{~m}^{-2}$, which is about $10 \%$ of the maximum downward surface solar flux in the Sierra Mountains area, are found on the east side of the mountains facing the sun, while negative anomalies are located on the west side due to the shadow effect (Fig. 3a and b). In the afternoon, since the sun moves to the west, positive deviations are located on the west side of the mountains while negative 
(a)

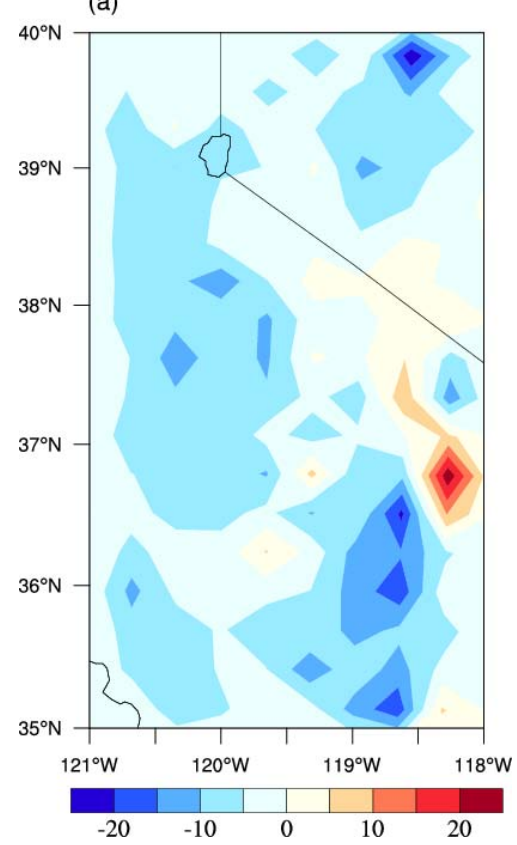

(b)

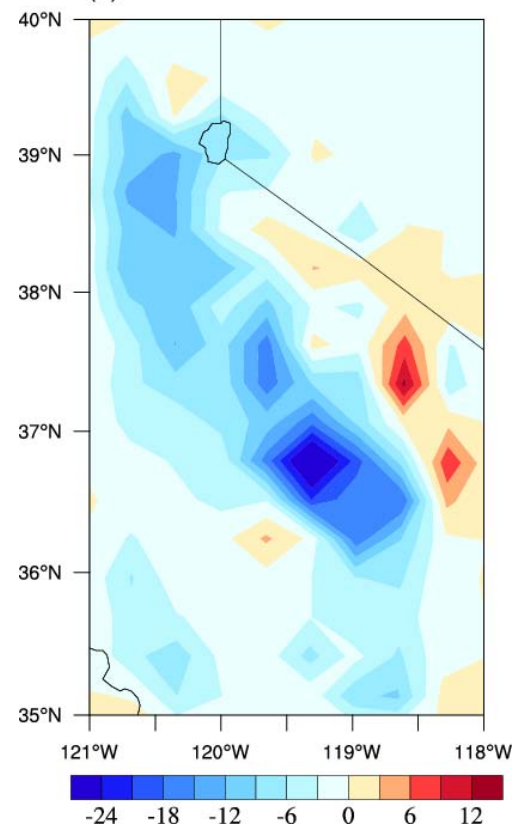

(c)

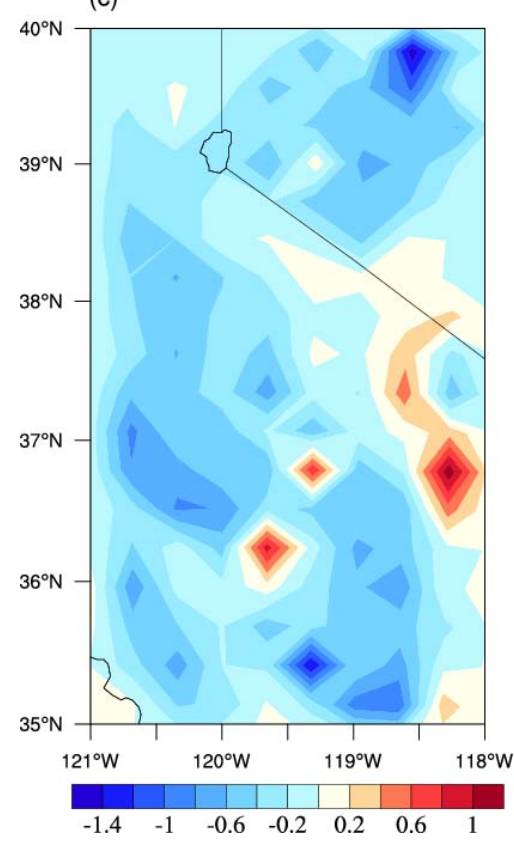

(d)

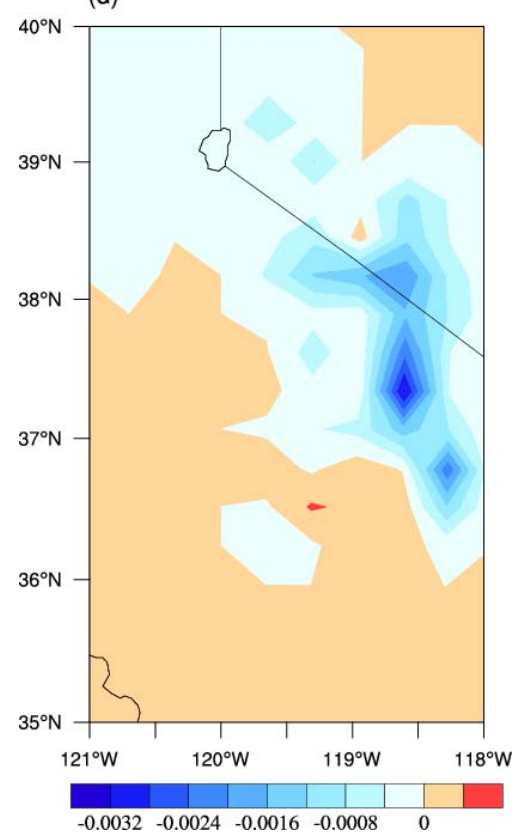

(e)

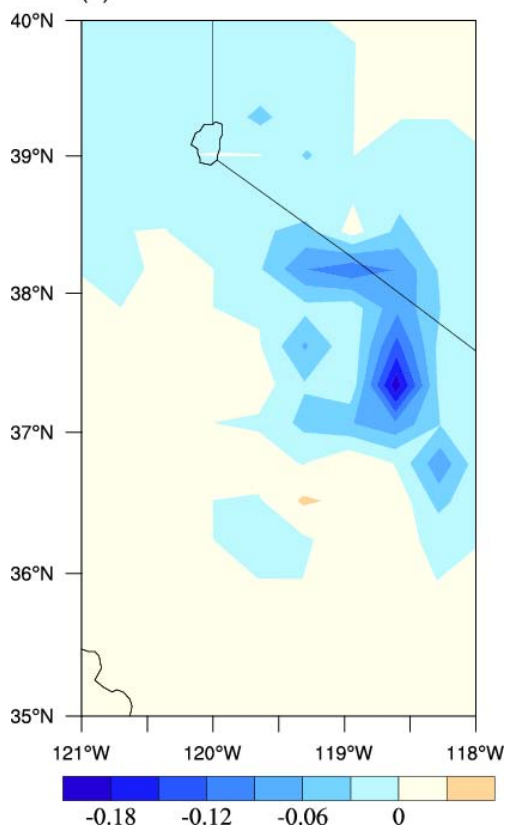

(f)

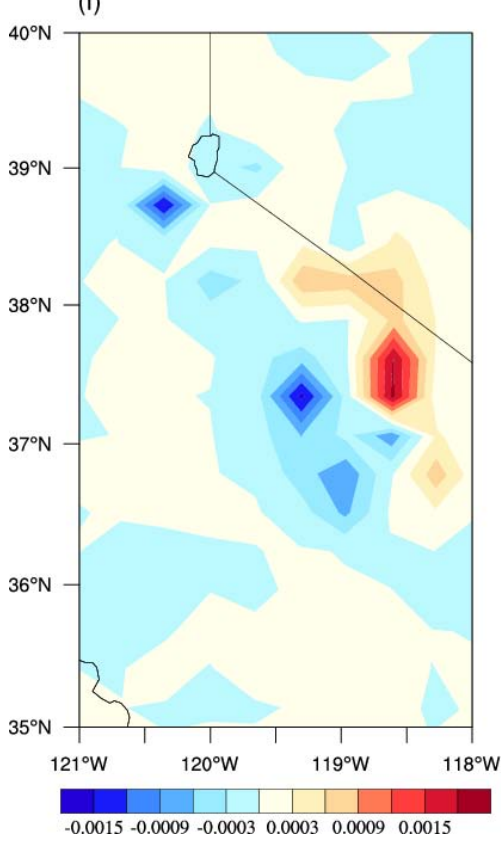

Fig. 4. Differences in the (a) sensible heat flux $\left(\mathrm{W} \mathrm{m}^{-2}\right)$, (b) latent heat flux $\left(\mathrm{W} \mathrm{m}^{-2}\right)$, (c) surface skin temperature $(\mathrm{K})$, (d) surface albedo, (e) snow water equivalent $\left(\mathrm{kg} \mathrm{m}^{-2}\right)$, and (f) soil moisture $\left(\mathrm{m}^{3} \mathrm{~m}^{-3}\right)$ between experiments RAD_3-D and CTRL at 9 a.m. on 29 March 2007.

values are displayed on the east (Fig. 3f). During the noon time, the flux deviations are smaller compared to the morning and afternoon cases because the sun is mostly overhead. Positive and negative deviations are located on the south and north side of the mountains because the position of the sun is to the south of the mountains at noon time. Note that the southern area is a valley with mountains located to both the north and south; hence it experiences more shadow effects and appears to be cooler (Fig. 3d).

Increases/decreases in the radiation field at the surface will affect surface processes. Figure $4 a-c$ shows the induced changes in the sensible heat flux, latent heat flux, and surface skin temperature at 9 a.m. on 29 March 2007. Clearly displayed are positive changes on the east side of the mountains and negative changes on the west, associated with the 
(a)

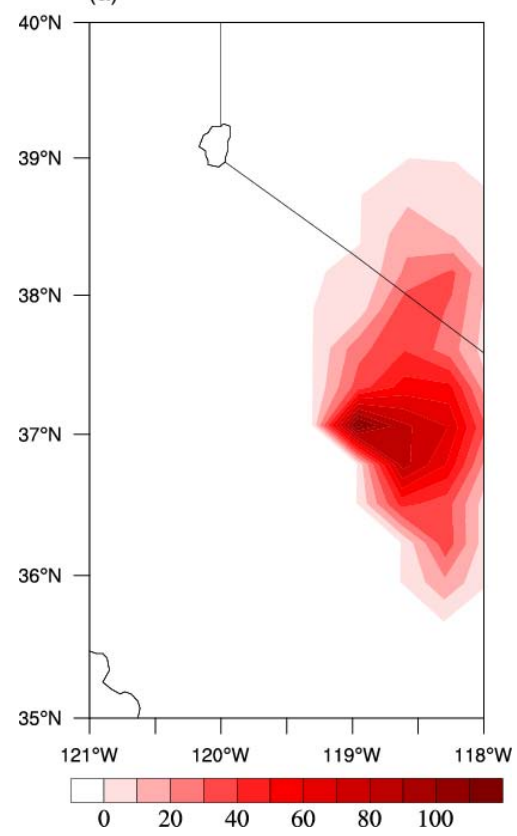

(b)

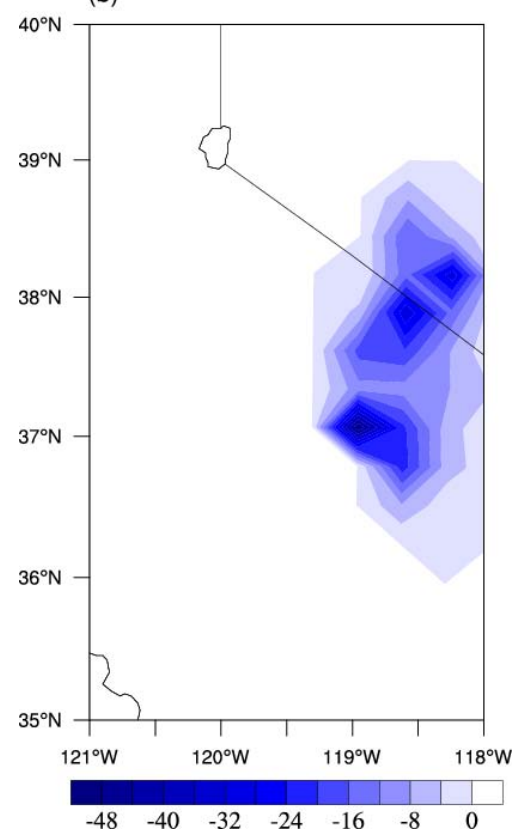

(c)

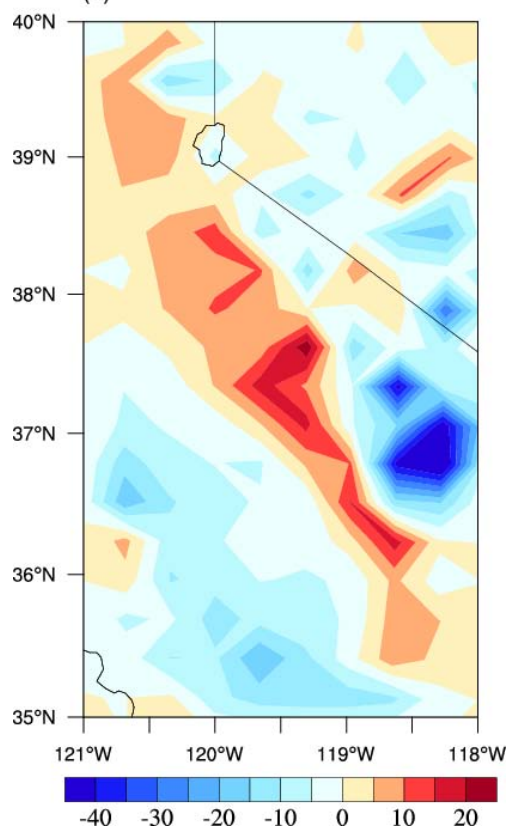

Fig. 5. (a) Cloud water path (CWP, $\mathrm{g} \mathrm{m}^{-2}$ ) simulated in the CTRL experiment, (b) differences in CWP due to the mountain effect, and (c) differences in surface solar insolation $\left(\mathrm{W} \mathrm{m}^{-2}\right)$ due to the mountain effect at 1 p.m. on 29 March 2007.

position of the sun and the corresponding deviations in surface solar fluxes. Differences in the sensible heat flux range between $-20 \sim 20 \mathrm{~W} \mathrm{~m}^{-2}$ (Fig. 4a), while they are between $-24 \sim 12 \mathrm{~W} \mathrm{~m}^{-2}$ for the latent heat flux (Fig. 4b), compensating the changes in surface solar fluxes. Consequently, surface skin temperature (Fig. 4c) shows increases on the sunny side (up to $\sim 1.0 \mathrm{~K}$ in the morning) and decreases on the shaded side $(\sim-1.4 \mathrm{~K})$. The effect of the 3-D mountain on the simulated surface albedo, snow water equivalent, and soil moisture in the top most soil layer is illustrated in Fig. 4d-f. Corresponding to positive changes in the surface solar insolation on the sunny side of the mountains, snow water equivalent and surface albedo both show decreases (Fig. 4d and e), indicating more snow melting and hence reduced snow albedo associated with more solar fluxes at the surface. Soil moisture increases on the sunny side of the mountains due to enhanced snowmelt, while decreases on the shade side (Fig. 4f).

Changes in the radiation field at the surface may also modulate the atmospheric processes. Figure 5 illustrates the cloud water path (CWP) simulated in the CTRL experiment, changes in CWP, and the associated changes in surface solar insolation due to mountain effect at 1 p.m. on March 29, 2007, when clouds have the maximum cloud water during that day. There was no synoptic frontal system over that area during the time period simulated in this study. Clouds began to form over the CWP area shown in Fig. 5a at about noon time, suggesting that clouds formed as a result of direct radiation effects. The clouds were low clouds, with no evidence of ice formation. These clouds likely developed in response to the solar heating, which gradually built up since the morning. As is common in mountain environments, upslope flow probably has contributed to convection and cloud formation as the elevated surface in mountains was heating up relative to the surrounding air, and such effect should be important from about $2 \mathrm{pm}$ to late afternoon when the differential heating between the mountain surface and the surrounding air is largest. A reduction in surface insolation can therefore reduce upslope flow and convection, leading to reduced CWP. Significant negative changes of up to $-40 \mathrm{~g} \mathrm{~m}^{-2}$ are found in the CWP (Fig. 5b), associated with reductions in the surface insolation over that region (Fig. 5c). Reduced solar insolation leads to cooling of the surface and weakening of convection over the region resulting in less cloud water. Since cloud formation is primarily dominated by dynamical processes, more surface heating over the south of the mountains may not lead to cloud formation in this case. For this reason, no changes are found in other regions.

\subsection{A discussion on potential climatic impact}

The mountain radiation effect significantly affects the spatial and temporal distributions of the surface solar insolation and other surface fluxes. Because the surface solar fluxes on each side of the mountains become enhanced when facing the sun and reduced when shaded, the overall changes of surface energy balance during a day may be cancelled out. In order to examine the potential climatic impact of the mountain 
(a)

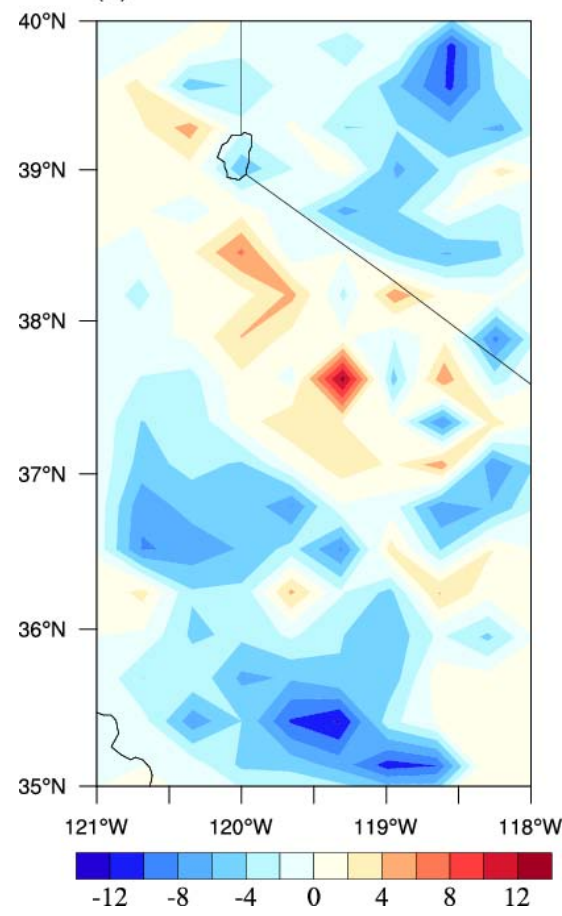

(c)

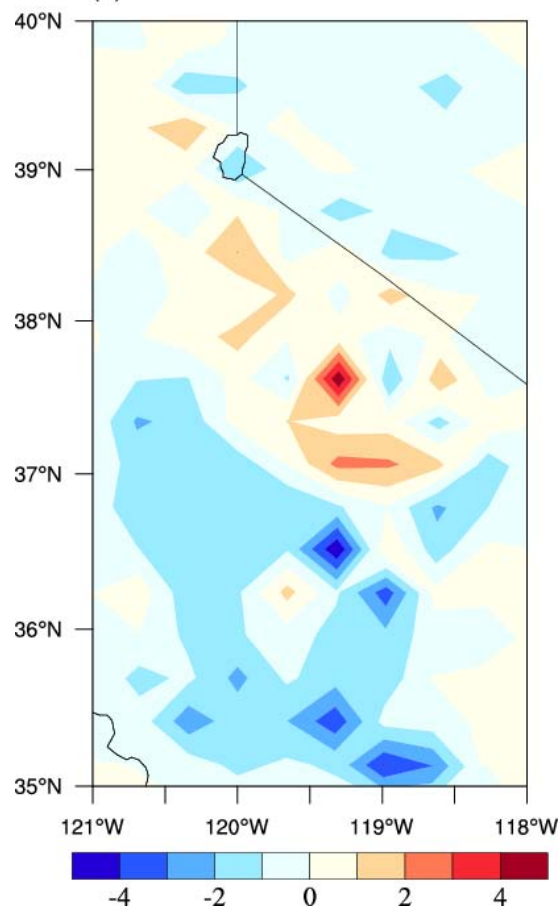

(b)

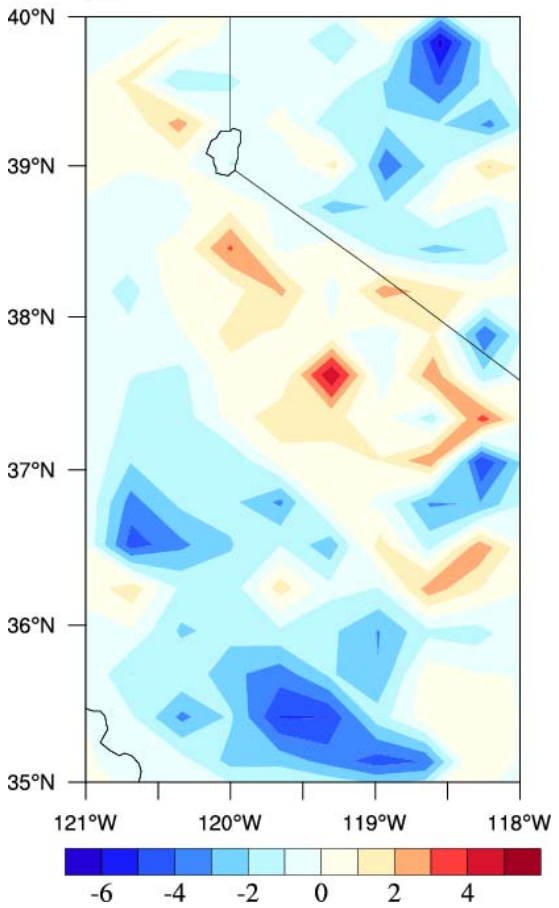

(d)

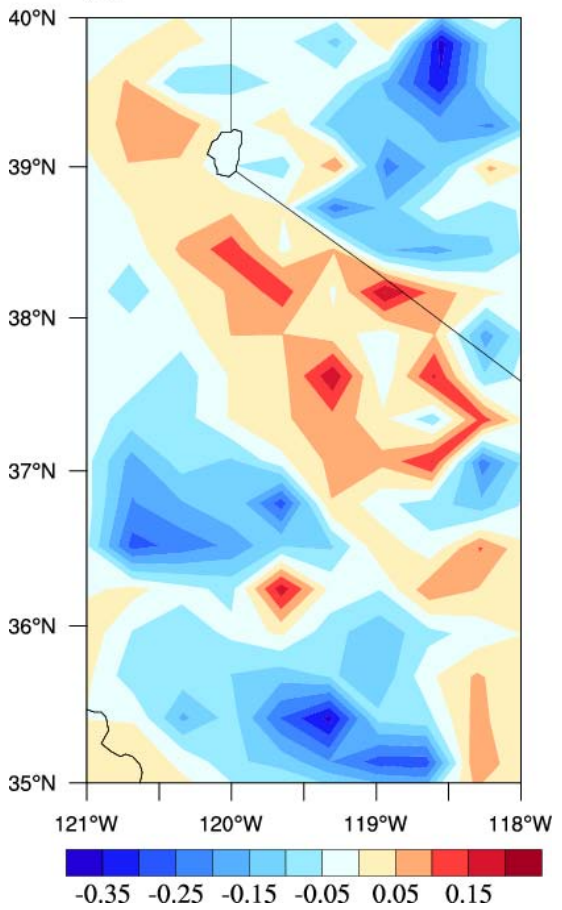

Fig. 6. Spatial distribution of the day-averaged deviations of (a) surface solar flux $\left(\mathrm{W} \mathrm{m}^{-2}\right)$, (b) sensible heat flux $\left(\mathrm{W} \mathrm{m}^{-2}\right)$, (c) latent heat flux $\left(\mathrm{W} \mathrm{m}^{-2}\right)$, and (d) surface skin temperature (K) over the Sierra-Nevada area on 29 March 2007.

effect on surface solar fluxes, we calculated a day-averaged distribution of solar fluxes over the Sierras. On 29 and 30 March 2007, the sunrise and sunset time is about 6 a.m. and 6 p.m., respectively. Thus, the hourly deviations of surface solar fluxes during 6 a.m.-6 p.m. are averaged and the spatial distributions are shown in Fig. 6. Positive day-averaged deviations of solar insolation are located over the mountain areas, while negative values are found mostly in the valleys, 
with a range between $-12 \sim 12 \mathrm{~W} \mathrm{~m}^{-2}$ (Fig. 6a). The reason that the valleys receive less solar insolation averaged over a day is related to the shadow effect of the mountains during both mornings and afternoons. Changes in the daily solar insolation, especially increases over the mountains, could significantly affect the mountain surface processes, including snowmelt, soil wetness, photosynthesis, vegetation, and evapotranspiration. Also increases/decreases over the mountains/valleys could modulate local atmospheric circulation, which requires in-depth study using a climate model. The corresponding day-averaged changes in sensible and latent heat fluxes (Fig. $6 \mathrm{~b}$ and c) and surface skin temperature (Fig. 6d) also show increases over the mountain areas and decreases in the low elevated regions, similar to the patterns in the surface solar fluxes. Differences in the sensible heat flux compensate about half of the changes in surface solar flux, while changes in latent heat flux account for the remaining half. Day-averaged temperature changes are found to be between $-0.35 \sim 0.15^{\circ} \mathrm{C}$, warming over the mountains and cooling over the valleys.

The diurnal variations of solar insolation over mountain surfaces are important to weather and climate predictions. The diurnal cycle is a significant characteristic over a region that is dominantly influenced by solar radiation over land. Differences in the domain-averaged diurnal variation over the Sierra-Nevada area on March 29, 2007 are shown in Fig. 7a. During the early morning and late afternoon, the mountain area receives more solar insolation (black). As a result, additional upward sensible heat and latent heat fluxes increase (red and blue), along with an increase in surface skin temperature (green). From about 8 a.m. to about 3 p.m., the surface insolation and heat fluxes present negative changes for this area, indicating a cooling effect. Consequently, domain-averaged temperature drops during this period. Overall, the diurnal amplitudes of surface fluxes and surface temperature are reduced over the whole SierraNevada area due to interactions between mountain and solar radiation. Note that the domain-averaged diurnal values depend on the selection of the area, such as the ratio of the area of mountain to that of valley. Since it is important to know how radiative effects affect the energy budgets in the mountains, where even a small difference in daily solar flux could have important accumulative effects on snowpack over the cold season and timing of snowmelt, we also examined the hourly differences in surface solar flux averaged for mountain regions above $1500 \mathrm{~m}, 2000 \mathrm{~m}$, and $2500 \mathrm{~m}$, respectively (Fig. 7b). It is shown that the pattern of the diurnal variations for regions above $1500 \mathrm{~m}$ (black) looks similar to that for the whole Sierra Mountain area, with maximum increases around 7 a.m. and 5 p.m. while a maximum reduction at 9 a.m.. However, the hourly changes for higher elevations begin to differ, with largest enhancement in the early morning at $7 \mathrm{a} . \mathrm{m}$. and the maximum reduction shifts to $10 \mathrm{a} . \mathrm{m}$. and 2 p.m. for regions above $2000 \mathrm{~m}$ (red). For elevations above $2500 \mathrm{~m}$, the largest decrease occurs only in the af-
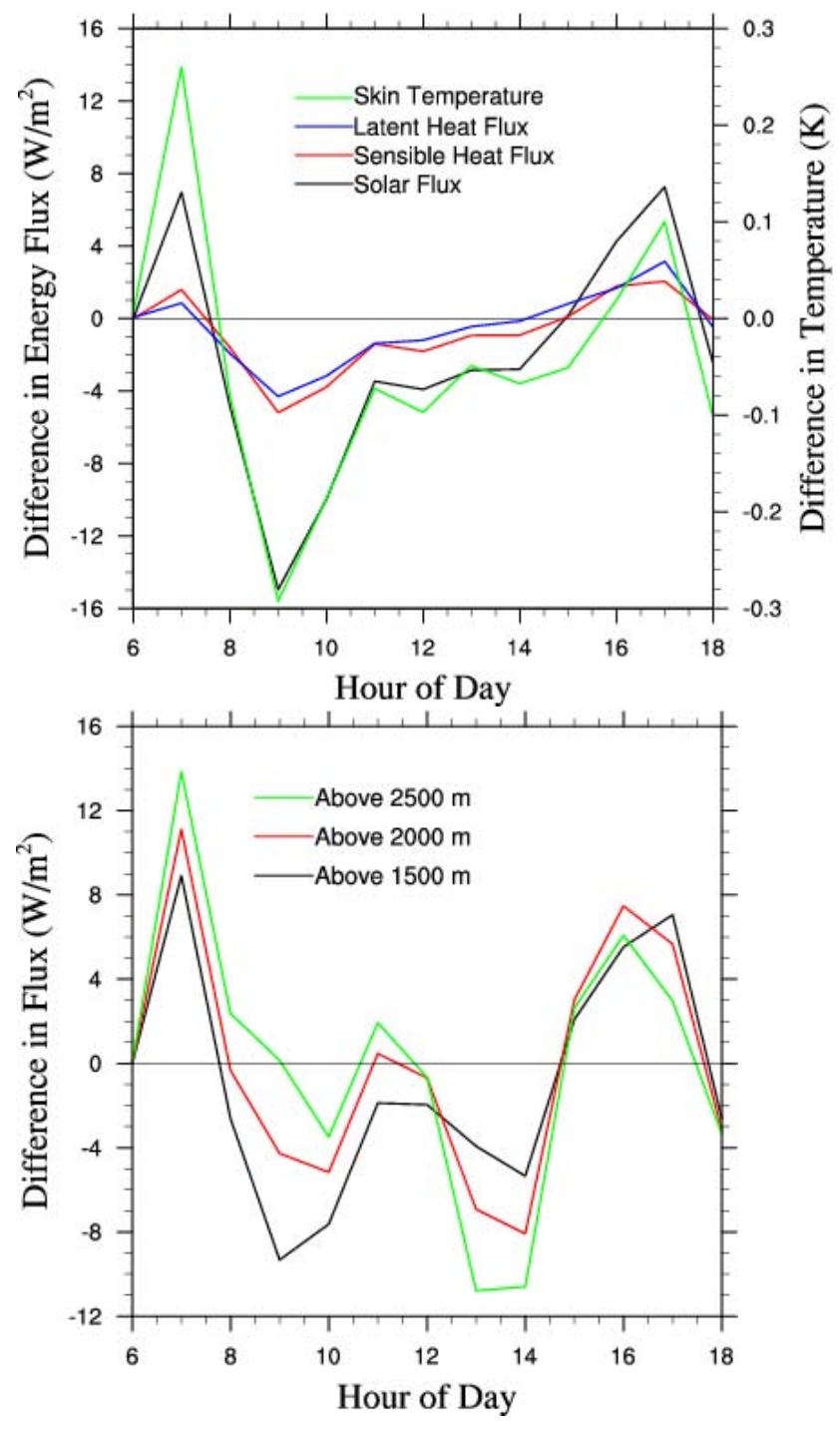

Fig. 7. Differences in the (a) domain-averaged diurnal variation of surface solar flux (black, $\mathrm{W} \mathrm{m}^{-2}$ ), sensible heat flux (red, $\mathrm{W} \mathrm{m}^{-2}$ ), latent heat flux (blue, $\mathrm{W} \mathrm{m}^{-2}$ ), and surface skin temperature (green, $\mathrm{K}$ ) and (b) domain-averaged diurnal variation of surface solar flux $\left(\mathrm{W} \mathrm{m}^{-2}\right.$ ) for mountain regions above $1500 \mathrm{~m}$ (black), $2000 \mathrm{~m}$ (red), and $2500 \mathrm{~m}$ (green) over the Sierra-Nevada area on 29 March 2007.

ternoon around 2 p.m. (green). The maximum reduction of surface solar flux over higher elevations at 2 p.m. is likely due to the topographic characteristics of the Sierras, which have sharper cliffs over the northeast side of the mountains (see Fig. 1). Therefore, for higher elevations, a portion of the northern slopes will be shadowed even when the position of the Sun is at 2 p.m., during which the available solar flux is near its maximum, leading to the maximum reduction of surface solar flux. When lower elevations are included, most of the lower mountain areas are visible to the Sun. Because the higher elevated region only constitutes a portion of the total area, reduction at $2 \mathrm{pm}$ becomes smaller. Note that clouds do 
not contribute to the difference in timing of maximum reduction at the higher and lower elevations. Clouds only began to form around noon and occurred mainly at the higher elevation. Cloud water path was found to decrease due to mountain effects that reduced surface solar flux, so the cloud response is to compensate partly for the solar flux change rather than to shift the maximum reduction of solar flux to 2 p.m. The negative changes during the middle of the day become smaller in magnitude with increasing elevations. Overall, more solar fluxes are received during the whole day for the higher elevated mountain regions, as also shown in Fig. 6 a.

\section{Conclusions}

We have incorporated a 3-D radiative transfer parameterization over mountains in WRF to improve the understanding of the effect of 3-D inhomogeneous and complex mountains on the distribution of solar insolation at mountain surfaces and subsequent impact on land-surface processes in terms of sensible and latent heat fluxes and skin temperature. Using the Sierra-Nevada in the Western United States as a testbed, the model simulation results show that the mountain effect would produce up to $-50 \sim 50 \mathrm{~W} \mathrm{~m}^{-2}$ deviations in the surface solar fluxes, resulting in a temperature change of up to $\pm 1^{\circ} \mathrm{C}$. Upward surface sensible and latent heat fluxes are modulated accordingly to compensate for the changes in surface solar fluxes. Decreased snow water equivalent and surface albedo are found on the sunny side of the mountains corresponding to the enhanced solar insolation and hence snowmelt. Soil moisture shows increase/decrease on the sunny/shade side. Larger differences are found in the morning during 8$10 \mathrm{a} . \mathrm{m}$. and in the afternoon around 3-5 p.m., while the differences around noon time and in the early morning and late afternoon are relatively smaller. Changes in surface energy balance over the mountains can also affect convection and modulate the atmospheric processes. Corresponding to reductions in the surface insolation over the cloud region, negative changes of up to $-40 \mathrm{~g} \mathrm{~m}^{-2}$ are found in the cloud water path. During winter/spring when cloud formations are more dominantly controlled by synoptic systems, changes in cloud formations due to mountain effect on solar radiation are relatively small, as shown in this case study. During summer when convection is largely driven by surface heating, asymmetry on the east/west slope of mountains and changes in surface solar fluxes can influence the diurnal timing and intensity of convection and precipitation (Johnson et al., 2010). This deserves further investigation particularly for mountains in which summer precipitation dominates the hydrological cycle.

To investigate the potential climatic impact of mountain effect on surface solar fluxes, the day-averaged spatial distribution and domain-mean surface fluxes and the domainaveraged diurnal variations over the Sierra-Nevada have been examined. It is shown that the day-averaged deviations are positive over the mountain areas and negative in the valleys, with a range between $-12 \sim 12 \mathrm{~W} \mathrm{~m}^{-2}$. Changes in the sensible and latent heat fluxes and surface skin temperature follow the pattern in solar insolation. The differences in the domain-averaged diurnal variation over the Sierra-Nevada Mountain area show that this area receives more solar insolation during the early morning and late afternoon, resulting in more upward sensible and latent heat fluxes from the surface and a corresponding increase in surface skin temperature. During the middle of the day, the surface insolation and heat fluxes present negative changes for this area, indicating a cooling effect. The hourly changes of the surface solar insolation in higher elevations show smaller magnitude in decrease during the middle of the day and possibly more solar fluxes received during the whole day. The notable changes in day-averaged spatial distributions and diurnal variation of the surface fluxes over the mountainous areas could significantly affect surface processes, including snowmelt, soil wetness, photosynthesis, vegetation, and evapotranspiration, as well as the local atmospheric circulation. Future work is planned for an in-depth study using an appropriate climate model coupled with a detailed LSM to simulate the longterm 3-D radiative effects over mountains..

Acknowledgements. This research has been supported by DOE Earth System Modeling program Grant DESC0006742. PNNL is operated for the US DOE by Battelle Memorial Institute under contract DE-AC06-76RLO1830.

Edited by: Q. Fu

\section{References}

Beljaars, A. C. M.: The parameterization of surface fluxes in largescale models under free convection, Q. J. Roy. Meteor. Soc., 121, 255-270, 1994.

Bonan, G. B.: Ecological Climatology: Concepts and Applications, Cambridge Univ. Press, New York, USA, 678 pp., 2002.

Chen, F., and Dudhia, J.: Coupling an advanced land-surface/ hydrology model with the Penn State/ NCAR MM5 modeling system. Part I: Model description and implementation. Mon. Weather Rev., 129, 569-585, 2001.

Chen, Y., Hall, A., and Liou, K. N.: Application of threedimensional solar radiative transfer to mountains, J. Goephys. Res., 111, D21111, doi:10.1029/2006JD007163, 2006.

Dyer, A. J. and Hicks, B. B.: Flux-gradient relationships in the constant flux layer, Q. J. Roy. Meteor. Soc., 96, 715-721, 1970.

$\mathrm{Fu}, \mathrm{Q}$. and Liou, K. N.: On the correlated $k$-distribution method for radiative transfer in nonhomogeneous atmospheres, J. Atmos. Sci., 49, 2139-2156, 1992.

$\mathrm{Fu}, \mathrm{Q}$. and Liou, K. N.: Parameterization of the radiative properties of cirrus clouds, J. Atmos. Sci., 50, 2008-2025, 1993.

Geiger, R.,: The Climate Near the Ground, Harvard Univ. Press, Cambridge, 611 pp., 1965.

Gu, L., Baldocchi, D., Verma, S. B., Black, T. A., Vesala, T., Falge, E. M., and Dowty, P. R.: Advantages of diffuse radiation for 
terrestrial eco-system productivity, J. Geophys. Res., 107, 4050, doi:10.1029/2001JD001242, 2002.

Gu, Y., Liou, K. N., Chen, W., and Liao, H.: Direct climate effect of black carbon in China and its impact on dust storms, J. Geophys. Res., 115, D00K14, doi:10.1029/2009JD013427, 2010.

Gu, Y., Liou, K. N., Ou, S. C., and Fovell, R.: Cirrus cloud simulations using WRF with improved radiation parameterization and increased vertical resolution, J. Geophys. Res., 116, D06119, doi:10.1029/2010JD014574, 2011.

Hong, S.-Y. and Pan, H.-L.: Nonlocal boundary layer vertical diffusion in a medium-range forecast model, Mon. Weather Rev., 124, 2322-2339, 1996.

Johnson, R. H., Ciesielski, P. E., L'Ecuyer, T. S., and Newman, A. J.: Diurnal cycle of convection during the 2004 North American Monsoon Experiment, J. Clim., 23, 1060-1078, 2010.

Kain, J. S. and Fritsch, J. M.: A one-dimensional entraining/detraining plume model and its application in convective parameterization, J. Atmos. Sci., 47, 2784-2802, 1990.

Kain, J. S. and Fritsch, J. M.: Convective parameterization for mesoscale models: The Kain-Fritcsh scheme, The representation of cumulus convection in numerical models, edited by: Emanuel, K. A. and D. J. Raymond, Amer. Meteor. Soc., 246 pp., 1993.

Lee, W. L. and Liou, K. N.: A coupled atmosphere-ocean radiative transfer system using the analytic for-stream approximation, J. Atmos. Sci., 64, 3681-3694, 2007.

Lee, W. L., Liou, K. N., and Hall, A.: Parameterization of solar fluxes over mountain surfaces for application to climate models, J. Geophys. Res., 116, D01101, doi:10.1029/2010JD014722, 2011.

Lee, W.-L., Liou, K. N., and Wang, C.-C.: Impact of 3-D topography on surface radiation budget over the Tibetan Plateau, Theor. Appl. Climatol., doi:10.1007/s00704-012-0767-y, 2012.

Lin, Y.-L., Farley, R. D., and Orville, H. D.: Bulk parameterization of the snow field in a cloud model, J. Climate Appl. Meteor., 22, 1065-1092, 1983.
Liou, K. N.: An Introduction to Atmospheric Radiation, 2nd ed., 583 pp., Academic, San Diego, California, USA, 2002.

Liou, K. N., Lee, W.-L., and Hall, A.: Radiative transfer in mountains: Application to the Tibetan Plateau, Geophys. Res. Lett., 34, L23809, doi:10.1029/2007GL031762, 2007.

Liou, K. N., Gu, Y., Lee, W., Chen, Y., and Yang, P.: Some unsolved problems in atmospheric radiative transfer: Implication on climate research in the Asia-Pacific Region, in: Recent Progress in Atmospheric Sciences: Applications to the Asia-Pacific region, World Scientific Publishing Co., Singapore, 307-325 pp., 2008.

Müller, M. D. and Scherer, D.: A grid- and subgrid-scale radiation parameterization of topographic effects for mesoscale weather forecast models, Mon. Weather Rev., 13, 1431-1442, 2005.

Paulson, C. A.: The mathematical representation of wind speed and temperature profiles in the unstable atmospheric surface layer, J. Appl. Meteor., 9, 857-861, 1970.

Rutledge, S. A., and Hobbs, P. V.: The mesoscale and microscale structure and organization of clouds and precipitation in midlatitude cyclones. XII: A diagnostic modeling study of precipitation development in narrow cloud-frontal rainbands, J. Atmos. Sci., 20, 2949-2972, 1984.

Skamarock, W. C., Klemp, J. B., Dudhia, J., Gill, D. O., Barker, D. M., Wang, W., and Powers, J. G.: A description of the Advanced Research WRF Version 2, NCAR Tech. Note 468+STR, 88 pp., Natl. Cent. for Atmos. Res., Boulder, CO, USA, 2005.

Webb, E. K.: Profile relationships: The log-linear range, and extension to strong stability, Q. J. Roy. Meteor. Soc., 96, 67-90, 1970.

Zhang, D.-L. and Anthes, R. A.: A high-resolution model of the planetary boundary layer - sensitivity tests and comparisons with SESAME-79 data, J. Appl. Meteor., 21, 1594-1609, 1982. 